\title{
Determinismo genético, genocracia, multiculturalidad, diversidad sexual y nuevos derechos: una mirada en torno a la creación de familias homoparentales * Genetic determinism, genocracy, multiculturalism, sexual diversity and new rights: a look around creation of homosexual families
}

Amparo de Jesús Zárate Cuello

Profesora Universidad Militar Nueva Granada amparo.zarate@unimilitar.edu.co

Luis Gustavo Celis Regalado

Recibido: 28/05/2016 Aprobado: 18/10/2016

Profesor Universidad de la Sabana

DOI: http://dx.doi.org/10.25054/16576799.1291

luis.celis@unisabana.edu.co

\section{RESUMEN}

Al presentarse la alternativa de creación de familia por parte de personas de un mismo sexo y de diferentes diversidades sexuales, género, orientaciones e identidades en acopio de las técnicas de fecundación humana asistida, se tiene la posibilidad de determinar genéticamente las características deseables de los seres humanos que pretenden traer a sus alianzas afectivas y constituir así la familia homoparental del deseo, con el genotipo y fenotipo que corresponda al prototipo ideal según los estándares de aceptación social. Sin embargo, estos tópicos generan problemas a la bioética y prenden las alarmas del bioderecho ante la intención de crear hijos con los avances de las biociencias, donde prima facie, campea la maternidad subrogada entre gays, lesbianas, bisexuales, transexuales, transgéneros, e intersexuales que podrían además organizar tríos y grupos poliamorosos, donde la maternidad y paternidad se extiende a los miembros de los mismos y por ende surgen nuevos derechos filiales para el nasciturus, dentro de los paradigmas de la multicuturalidad en la sociedad globalizada.

\section{PALABRAS CLAVE}

Bioderecho; bioética; determinismo genético; diversidades sexuales; genocracia; modelos familiares.

\begin{abstract}
Once it is presented the alternative of creation of a family by people of the same sex and different sexual diversity, gender orientations and identities according to the assisted human conception techniques, there is the possibility of genetically determine the desirable characteristics of human beings. What is pretend is to bring to their affective alliances and thus build the homosexual family of desire with the genotype and phenotype that corresponds to the ideal prototype of the social acceptance standards.
\end{abstract}

* Este artículo se deriva de la investigación HUM 1898, financiada por la Vicerrectoría de Investigaciones de la UMNG, vigencia 2015. 
However, these issues create problems to bioethics and turn on the biolaw alarms facing the intention of create children with advances in bioscience, where prima facie stands surrogacy maternity between gays, lesbians, bisexuals, transsexuals, transgender, and intersex. All of them could organize trios and polyamorous groups where maternity and paternity is extended to members of the same groups and therefore there are new filial rights for the unborn within the paradigms of multiculturalism in the global society.

\section{KEYWORDS}

Bioethics; bio-law; genetic determinism, genocracy; family models; sexual diversity.

\section{INTRODUCCIÓN}

"No todo lo que la ciencia puede-tecnológicamenterealizar, se puede -éticamente-hacer" (Javier Gafo)

El conocimiento es un misterio fascinante en la actualidad, es poder y dominio. Un ejemplo manifiesto de esto es el Proyecto Genoma Humano, el cual tenía por objeto: identificar y caracterizar la información contenida en cada cromosoma humano, elaborar mapa físico y genético, secuenciar los genes y archivarlos en genotecas y el desarrollo de nuevos métodos diagnósticos y terapéuticos.

Este estudio tiene nobles intenciones en el futuro: podríamos abaratar medicinas costosas, aliviar el hambre que padece gran parte de la humanidad, corregir defectos genéticos 0 detener el deterioro microambiental, pero además es un poderoso instrumento para intervenir la vida humana aún antes de la procreación (tecnofecundación) y una herramienta para diseñar organismos patógenos extraordinariamente virulentos 0 del producir hombres ala medida.

Los conocimientos derivados de esta investigación condujeron a la conclusión de que nuestro genoma está constituido por aproximadamente por unos 25.000 genes. Antes se estimaba en unos 100.000 genes y se dio inicio a los que podríamos llamar la 'Nueva Genética', cuyo origen lo podríamos ubicar en el año 1953 cuando los Des. James Watson y Francis Crick publican en Mayo de 1953 en la revista Nature la estructura del Ácido de Desoxiribunocleico (ADN).
Antes de 1953, la Genética Clásica realizaba el diagnóstico de la enfermedad de una manera netamente clínica es decir por su fenotipo, había una eugenesia positiva o negativa de acuerdo a estas características y no se presentaba una intervención directa sobre el patrimonio genético humano. Pero una vez se dilucido la estructura del ADN y en especial con el desarrollo de la biotecnología, la Nueva Genética permitió conocer los distintos procesos del genoma, la puesta en punto de diversas técnicas moleculares como la del ADN recombinante (que permitió entre otras cosas la transgénesis) y finalmente la posibilidad de realizar una intervención directa sobre el Genoma. Todo esto ha permitido que la Genética se haya constituido también en una industria a partir de la modificación de organismos biológicos o de células tanto microbianas, vegetales, animales y vegetales con diversos fines y ha abierto un abanico de posibilidades en distintos sectores como el sector salud, el agropecuario, el industrial, el minero, el energético y el medioambiental. De hecho las Artes Plásticas no han escapado a este fenómeno y autores como Eduardo Kac han acuñado términos como el 'Bioarte' para referirse a la modificación de organismos vivos mediante la inserción de genes que les confieran características como la fluorescencia.

Estos organismos fluorescentes brillan en presencia de luz ultravioleta al ser observados, dependiendo del tipo de fluorocromo utilizado con colores que van desde el verde hasta el rojo. Esto ha traído algunos reparos desde el punto de vista ético en el sentido de qué pasa con estas bacterias, peces, ratones, conejos, cerdos, perros, gatos y flores que han sido 
manipulados genéticamente para que brillen y llegasen a ser liberados accidentalmente al medio ambiente; de hecho en Taiwán hay una compañía denominada TKT que realiza modificaciones de peces cebra con genes fluorescentes provenientes de la anémona de mar o de color rojo al insertar genes obtenidos del coral.

\section{CIENCIAS ÓMICAS}

Otra consecuencia importante fue el desarrollo de la ciencias ómicas por que se comprendió que no sólo bastaba identificar y caracterizar la estructura del genoma (genómica estructural) sino que también era necesario conocer su función (genómica funcional), desarrollándose por lo tanto la Transcriptómica, la Proteómica, la Metabolómica (donde se identifican el reactoma, el interactoma y el degradoma) y el Fisioma, todo ello enmarcado en el Epigenoma y el Socioma, es decir que hemos llegado del Genoma hasta el Fenoma (del genotipo al fenotipo).

Dentro de este surgimiento de nuevas esferas del conocimiento derivadas, surgió la Medicina Genómica que busca:

- Desarrollar nuevas pruebas moleculares para el diagnóstico, la identificación de futuros riesgos para la salud o la predicción de la respuesta a determinados fármacos como el caso de la Farmacogenética y la Nutrigenómica.

- Comprender los mecanismos fisiopatológicos de algunas enfermedades, dado que una vez que se conoce el proceso alterado, se pueden realizar distintas intervenciones.

- Desarrollar nuevos métodos diagnósticos y terapéuticos para desordenes genéticos tanto raros como comunes.

La Biomedicina por tanto debe estar al servicio del hombre no para dominarlo, no para transformarlo en cosa o negocio. Las decisiones humanas constituyen el campo específico de la reflexión ética, la ciencia y la técnica son acciones y por lo tanto están sujetas a esta, adicionalmente de que estas acciones pueden ser consideradas buenas o malas, el progreso no puede ser un proceso autónomo desligado de la ética, el científico no es neutro dado que los experimentos que involucren seres vivos que son capaces de sentir como en el caso de la investigación biomédica necesariamente conducen a una reflexión bioética.

\section{PROBLEMAS ÉTICOS}

Los problemas éticos derivados de la investigación genética están en plena efervescencia en el momento actual; la investigación del genoma se está convirtiendo en un nuevo foco del capitalismo, transformando la ética en monética y dando origen a una nueva fiebre del oro porque las grandes compañías han percibido la importancia de patentar los genes humanos (lo cual ha dado origen a una gran controversia), motivadas a que partir de estos, debe desarrollarse la biomedicina del siglo XXI, generándose nuevos elementos tanto diagnósticos como terapéuticos.

Otra grave preocupación que ha surgido de estas investigaciones es el determinismo genético basado en una excesiva genomización del hombre, que pretende explicar todas sus dimensiones a partir de sus genes; así tenemos el gen del egoísmo, de la delincuencia, de la obesidad, de la violencia, de la homosexualidad y otros. Si bien, la parte biológica del hombre (incluyendo la genética) es muy importante, no se puede atribuir todas las conductas del hombre a ella; esto eliminaría la responsabilidad individual de cada uno y se perdería el sentido de la ética, quedando reducido todo a lo que tenemos en los genes.

Después surgiría la eugenesia genética embrionaria, porque podríamos desechar a los individuos que porten características no deseadas o que no estén de acuerdo a la moda 0 al estereotipo actual. En este caso estaríamos haciendo una selección positiva o negativa de individuos; todo esto nos conducirá a una genocracia (dictadura de los genes), en donde el poder de los genes será una dictadura y todo lo que esté por debajo de lo normal va camino al despeñadero, como los aguerridos Espartanos de la antigua Grecia que arrojaban por los desfiladeros 
a los niños deformes. En el siglo XXI los arrojaremos al precipicio genético, por ejemplo, cuando seleccionamos de acuerdo a nuestro interés un determinado genotipo no deseado.

En este momento hacemos un alto en el camino y declaramos que el hombre no es propiedad de la genética. El reduccionismo biológico no enaltece al hombre sino que lo despoja de su libertad, por lo tanto serían inútiles las campañas preventivas de enfermedades como el alcoholismo, la igualdad de oportunidades o la de educación para todos, dado que todo está determinado de antemano (sobre todo en los genes); de no reflexionar y actuar rápidamente, el hombre asumirá, sino lo ha hecho ya, el papel del creador.

En este orden de ideas, el determinismo genético constituye una gran falacia que pretende dejar de lado la responsabilidad individual para sustituirla por un factor inmutable y determinado que son los genes. Esto nos conlleva a un concepto univoco del instinto y que no toma en cuenta la heterogeneidad del mismo, donde el ambiente tanto biológico como cultural interacciona con los genes y modela elementos como lo irascible y lo concupiscible.

Cuando se desconoce esta dimensión del hombre y se le reduce a un plano meramente biológico se justifican todo tipos de conductas como la infidelidad ("deseo serte fiel pero estos genes que llevo dentro me lo impiden") o la homosexualidad; si bien algunos trastornos cromosómicos pueden llevar a una ambigüedad sexual, muchos de los casos reportados son de tipo adquirido por fenómenos como el hacinamiento en las cárceles, la falta de una figura paterna en la educación o una educación sexual centrada tan sólo en la prevención de enfermedades de transmisión sexual y los embarazos no deseados.

\section{ASPECTOS GENÉTICOS DE LA DIVERSIDAD SEXUAL}

En los últimos años, diversos grupos han realizado estudios tratando de establecer diferencias entre las personas homosexuales y los heterosexuales, lo cual resulta muy complejo dado que la conducta humana tiene un origen multifactorial producto de la interacción gen - ambiente. Los distintos estudios se han centrado principalmente en la estructura del cerebro o la presencia de distintos genes que se han pretendido asociar a la homosexualidad.

Uno de los primeros estudios fue el realizado por Le Vay (1991), que estudió el desarrollo de los núcleos intersticiales (que son cuatro grupos neuronas cercanas al hipotálamo), encontrando que las del grupo 3 en las personas homosexuales eran de menor tamaño que en los heterosexuales. A partir de este hallazgo se realzaron extrapolaciones basadas en que en el caso de las mujeres este núcleo intersticial es de menor tamaño que en el hombre. Una de las primeras observaciones que se hicieron a este trabajo era que los cerebros estudiados provenían de pacientes con SIDA por lo que la alteración era producto de la infección y no de una alteración constitucional; por otra parte, habría que establecer la relación entre el tamaño del núcleo intersticial 3 con la tendencia sexual para establecer una relación causa - efecto.

Otro estudio fue el realizado por Hammer (1993), que al analizar el árbol genealógico de 114 familias con algún miembro homosexual para buscar una relación de parentesco entre los miembros de tendencia, asoció un marcador genético presente en el cromosoma $X$ que consistía en la ausencia de microsatélites en la posición Xq28, encontrando que en 40 de las familias estudiadas había una relación entre este marcador y el comportamiento homosexual, llegándose a postular a la homosexualidad como una enfermedad genética OMIM 306995.

Este estudio fue replicado en tres ocasiones con resultados diversos. En uno se obtuvieron similares resultados, en otro no hubo diferencias estadísticas significativas y en un tercero no se encontró ninguna asociación.

Otras causas se han atribuido a la exposición de altos niveles de testosterona o estrógenos en el útero que 
pudiesen originar cambios epigenéticos 0 deficiencias en la biosíntesis del cortisol producto de la HiperplasiaAdrenal Congénita (CAH).

Finalmente, debemos afirmar que estos estudios no son concluyentes y hay que estudiar cada caso en particular, por que como antes fue mencionado al ser la conducta humana multifactorial, no pueden establecerse causas únicas y mucho menos caer en el determinismo genético que pretende suprimir la libertad humana y que toda conducta humana sea producto de la composición genética de los individuos en forma inalterable e irreversible.

\section{MULTICULTURALIDAD, DIVERSIDAD SEXUAL $Y$ NUEVOS DERECHOS: CREACIÓN FAMILIAS HOMOPARENTALES}

Desde el punto de vista legal, el matrimonio se concibe como una unión socialmente aceptada, generalmente entre un hombre y una mujer ${ }^{1}$, la cual está regulada tanto por la ley como por distintos factores sociales tales como valores, costumbres, creencias y actitudes, que prescriben los derechos y deberes de los sujetos implicados.

En lo concerniente específicamente al matrimonio entre personas del mismo sexo, si bien durante muchos años ésta fue una práctica prohibida no sólo por la religión sino por diversos sectores sociales alrededor del mundo; en los albores del siglo XXI un sinnúmero de países ya han regulado dicho tipo de uniones, empezando por Canadá, de manera tal que han sido creadas varias leyes y normas que les confieren igualdad de derechos frente a las parejas heterosexuales, equiparando así la naturaleza de ambas.

Aunque en principio se podría afirmar que la homosexualidad se encuentra enmarcada dentro del espectro de la personalidad comprendiendo, al igual que los heterosexuales, una serie de con- ductas acordes a los comportamientos socialmente aceptados con relación al ejercicio de roles tales como la paternidad, algunos psiquiatras como Enrique Rojas (citado por Delgado. 2004), han aportado varios argumentos acerca del efecto nocivo que las familias homoparentales pueden causar a los menores de edad, pues afectan el normal desarrollo de las estructuras de su personalidad y constituyen una especie de laboratorio psicológico cuyo resultado es incierto, en el cual el niño es sometido a tener dos padres o dos madres, e incluso dos padres y una madre, o dos madres y un padre, y demás variaciones de modelos familiares que han ido surgiendo con el transcurrir del tiempo.

No obstante, y aún cuando existen numerosos estudios que analizan cómo la conformación de familias homoparentales afectan el bienestar de los niños implicados y su normal desarrollo en los entornos familiar y social, las leyes diseñadas por los gobiernos de los distintos países han apuntado hacia el reconocimiento de los derechos de la comunidad LGBTI más que hacia el bienestar de los hijos que se conciban dentro de sus respectivas uniones, lo cual se traduce en una terrible omisión de los derechos de los menores que en teoría deberían ser imperantes.

En este sentido, es evidente que el derecho de las parejas homosexuales a formar una familia donde se incluyan hijos, ya sea a través de un proceso de adopción o un procedimiento de fecundación in vitro, ha primado sobre el derecho de los niños a tener un padre y una madre, como así lo determinan las leyes de la naturaleza.

Esto sugiere un problema adicional relacionado con la forma en que los hijos son concebidos en el marco de una familia homoparental, pues dada la imposibilidad de concebir entre personas del mismo sexo, éstas deben acudir a técnicas de fecundación asistida, dando lugar a otras acciones como por ejemplo las modificaciones genéticas al nasciturus,

1. Tal como lo afirma la Declaración Universal de los Derechos Humanos en su artículo 16 (citado por Zárate, 2014, p.89), «los hombres y las mujeres a partir de la edad núbil, tienen derecho, sin restricción alguna por motivos de raza, nacionalidad o religión, a casarse y a fundar una familia». Así mismo, el Pacto Internacional de Derechos Civiles y Políticos reconoce, en su artículo 23.2, el "derecho del hombre y la mujer a contraer matrimonio y fundar una familia». 
de manera que:

La legislación colombiana se ha destacado entre otras cosas por una constante preocupación hacia el futuro y la posibilidad de elegir bebés (eugenesia positiva) puede dar lugar a una sociedad en que las discriminaciones comiencen antes del nacimiento. (...) Así, al otorgar esta libertad al científico, se produce una violación del derecho a la integridad física del ser humano, puesto que si el embrión es un ser humano y se le selecciona, no se está respetando ni su integridad física ni su vida. De igual manera, se viola el principio de igualdad entre los seres humanos.

Es así como se evidencian las distintas problemáticas que giran en torno a la conformación de familias homoparentales, pues no solamente está de por medio la conservación del modelo tradicional de familia que confiere a los niños la posibilidad de nacer en el seno de un hogar conformado por las dos figuras paternas, sino que además se incluyen en el debate aspectos tales como la fecundación asistida y la inseminación in vitro, la eugenesia positiva y la consiguiente discriminación de los nasciturus, el derecho de los niños dados en adopción a tener ambas figuras paternas $y$, más recientemente, la conformación de núcleos familiares compuestos por personas de un mismo sexo y de diferentes diversidades sexuales, género, orientaciones e identidades.

Aterrizando estas problemáticas al contexto colombiano, con relación a la procreación asistida en parejas homosexuales y heterosexuales, hasta hace algunos años el llamado "derecho a procrear" se reconocía solo a los matrimonios y a las parejas heterosexuales que probaran una convivencia estable, excluyendo la posibilidad de que mujeres solteras o parejas de homosexuales recurrieran a técnicas asistidas. Esto, dado que, en palabras de Paula Samper:

La legislación colombiana se ha destacado entre otras cosas por una constante preocupación hacia el futuro y estabilidad de la familia como un núcleo de la comunidad, y en este sentido aceptar la práctica de fecundación asistida en los eventos mencionados pone en tela de juicio la mencionada protección estatal a la familia.
Si bien con el tiempo se han ido introduciendo a la legislación colombiana algunos elementos que confieren igualdad de derechos a las parejas homosexuales y heterosexuales en lo referente a la paternidad, la política nacional y reproductiva del Estado, se ha enfocado más hacia los adolescentes, la maternidad segura, la protección y prevención de enfermedades de transmisión sexual, entre otras, restando cierta importancia a las técnicas de reproducción asistida. En este sentido, se hace evidente el desinterés del Estado colombiano en intervenir, reglamentar u orientar políticas públicas respecto a estas técnicas, siendo necesario, como afirma Monroy:

Ofrecer claridad al respecto ya que este tipo de técnicas vienen teniendo un desarrollo y efectividad cada vez más importante no solo a nivel de Colombia sino del mundo, y es el Estado el llamado a ofrecer no solo seguridad jurídica a los diferentes actores que intervienen en el proceso, sino también a los niños que nacen bajo este sistema, y el material genético que puede llegar a ser susceptible de manipulación.

Esta es justamente la principal razón por la cual se deben regular en Colombia las técnicas de reproducción asistida, pues los riesgos y consecuencias que acarrean no recaen necesariamente sobre las personas que desean ejercer su rol de paternidad, sea cual sea su identidad, género u orientación sexual, sino sobre los hijos y su normal desarrollo como individuos y seres sociales. En consecuencia, este es un debate que el Congreso colombiano debe dar de cara al país, al determinar, como bien lo hemos manifestado, "si las parejas unidas de un mismo sexo deben conformar una familia con hijos creados por las técnicas de fecundación in vitro; y la situación jurídica de éstos, o mantener incólume nuestras disposiciones de rango constitucional y legal que establece su conformación por un hombre y una mujer".

Dicho en otras palabras, en la protección de los derechos tanto del nasciturus como del niño que nace bajo las técnicas de reproducción asistida, están en juego aspectos fundamentales como la dignidad humana (inherente a toda persona), el derecho a la vida; el derecho a la integridad física, 
psicológica y existencial que condicionan el libre desarrollo de la personalidad; el derecho a una familia, a una identidad genética, y el derecho mismo a la identidad del nacido.

Dado que, como se ha dicho con anterioridad, en el país existe una ausencia de marcos legales que regulen la procreación humana asistida, los diferentes centros dedicados a esta actividad se han convertido en una opción o alternativa real tanto para parejas heterosexuales como homosexuales, partiendo del supuesto de que los particulares pueden hacer todo aquello que no les sea prohibido. En consecuencia, la realidad palpable es que "las técnicas de fecundación in vitro se realizan sin ningún tipo de control a quienes tengan el recurso económico para sufragar los costos de las mismas, sin distinción de orientación sexual" ni de ningún otro tipo (es decir, sin tener en cuenta el bienestar del futuro niño ${ }^{2}$.

En este sentido, el funcionamiento indiscriminado de los Centros de Reproducción Asistida en Colombia se podría considerar en contravía con la Constitución Política, pues como bien lo consagra el artículo 42 de la carta magna -citado por Monroy, 2013-: "los hijos habidos en el matrimonio o fuera de él, adoptados 0 procreados naturalmente 0 con asistencia científica, tienen igualdad de derechos y deberes. La ley reglamentará la progenitura responsable".

Al respecto valga aclarar, tal como lo afirma Jaima Sanz (2014), que "al fondo de todo este asunto se vislumbra lo que muchos han dado en llamar el derecho del deseo, esto es, que se tiene derecho a todo lo que es susceptible de obtenerse, no obstante llevarse por delante principios o derechos enraizados", como es el caso del derecho a tener un padre y una madre.
Uno de los casos más representativos en Colombia donde convergen ambos aspectos, el de la adopción y la fecundación in vitro por parte de parejas del mismo sexo, fue la batalla jurídica que emprendieron Ana Leiderman y Verónica Botero, una pareja de lesbianas, quienes luego de casarse en Alemania en el año 2005, tuvieron dos hijos y retornaron al país con la intención de radicarse y registrar a los menores con sus respectivos apellidos. No obstante, Cuando la pareja intentó registrar a la hija biológica de Ana, quien nació por inseminación artificial y por decisión de ambas, como hija por adopción de Verónica Botero, el ICBF negó la solicitud de adopción, la cual, según Germán Rincón, abogado de la pareja, fue producto de un acto de discriminación.

Fue así que la pareja de lesbianas inició una serie de acciones legales para defender su derecho a ser reconocidas como las madres de la menor y de su segundo hijo, quien nació en medio de la demanda (igualmente producto de técnicas de fecundación asistida), hasta que el 18 de agosto de 2014 la Corte Constitucional profirió un fallo (SU-617/14) por medio del cual se le otorgó a Verónica el derecho a fungir como madre de los hijos biológicos de Ana Leiderman, con quien convivía hace aproximadamente diez años. Este caso, como es bien sabido, abrió paso a la aprobación de la adopción por parte de parejas homosexuales en Colombia, razón por la cual el debate en torno a los derechos de los LGBTI se ha intensificado, pues estos han comenzado a exigir al gobierno y al aparato institucional del Estado, una serie de reformas a las leyes y normas colombianas a fin de garantizar la plena satisfacción de sus necesidades como comunidad.

Con relación a la adopción por parte de parejas del mismo sexo, el 19 de febrero de 2015 la Corte

2. Esto se contradice con lo que ha manifestado la Corte Constitucional en diferentes sentencias como la C-355 de 2006 (citada por Monroy, 2013), donde se ha referido al tema y afirma "Si la constitución protege la vida con la relevancia adecuada, no puede desprotegerla en aquella etapa de su proceso quien no sólo es condición para su vida independiente del claustro materno, sino que es también un momento del desarrollo de la vida misma; por lo cual ha de concluirse que la vida del nasciturus, cuando éste encarga un valor fundamental, la vida humana garantizada en el artículo 15 de la constitución, constituye un bien jurídico cuya protección encuentra en dicho precepto fundamento constitucional" (p.146). 
Constitucional expidió un fallo (C-071/15) $)^{3}$ concerniente al derecho de este tipo de uniones de acceder a la adopción plena.

No obstante, el tribunal declaró que sólo podrán hacerlo "cuando la solicitud recaiga en el hijo biológico de su compañero o compañera permanente". Posteriormente, el 4 de noviembre de 2015, profirió la Corte Constitucional la sentencia que les otorga la adopción plena a los homosexuales. La sentencia declaró exequible los artículos 64,66 y 68 de la Ley de Infancia y Adolescencia, bajo el entendido "que en virtud del interés superior del menor, dentro de su ámbito de aplicación están comprendidas también las parejas de un mismo sexo, que conforman una familia". Esto quiere decir, que por vía jurisprudencial la Sala Plena de la Corte Constitucional les otorgó la posibilidad de adoptar en forma plena a las parejas del mismo sexo o distintas diversidades sexuales, sin ningún tipo de restricción o regulación, primando el interés del niño a una familia sin importar el sexo de sus integrantes.

Un ejemplo de las conquistas de los LGBTI en Colombia, además del histórico fallo de la Corte Constitucional frente a la adopción, han sido las biopolíticas públicas impulsadas desde la Alcaldía Mayor de Bogotá en acompañamiento de algunas administraciones distritales, especialmente las de Luis Eduardo Garzón y Gustavo Petro.

En el año 2007, por mencionar algunos hitos, durante la administración de Luis Eduardo Garzón, se expidió el Decreto 608 del 28 de diciembre, por medio del cual se establecían los lineamientos de la política pública para la garantía plena de los derechos de las personas lesbianas, gay, bisexuales, transexuales e intersexuales LGBTI, en desarrollo de las dimensiones constitucionales, jurisprudenciales y del derecho internacional. Así mismo, durante la administración de Gustavo Petro se expidió el Decreto 149 de 2012, por medio del cual se modificó la estructura organizacional de la Secretaría Distrital de Integración Social, creando la subdirección para asuntos LGBTI.

Si bien a través de esta subdirección se ejecutó el proyecto 749 que pretendía promocionar el ejercicio y goce de los derechos de los LGBTI mediante programas

de atención a más de doce mil personas en situación de discriminación, exclusión y vulnerabilidad en diferentes centros de servicios; paralelamente no se han desarrollado políticas públicas o mecanismos legales que propendan por los derechos de aquellos que no tienen voz y se ven directamente perjudicados por los efectos de las políticas que favorecen a este grupo social.

En consecuencia, esto se traduce en una ausencia de Biolegislación en Colombia y en un choque de trenes institucionales entre el Congreso de la República y la Corte Constitucional, que han ido abriendo una ancha hendija para que la progenie se utilice como barricada para la consecución de derechos enmarcados en la diferencia; denominando este tipo de uniones, desde los debates ideológicos e intereses de la bandera política LGBTI, como "familias homoparentales". Ya no se trata únicamente de dos padres o dos madres, sino de dos madres y un padre, dos padres y una madre o familias poliamorosas, donde todos se aman entre sí y dicen tener progenie sin importar el número de padres o madres que el hijo forzosamente ostente en su ciclo vital, ampliándose el número de progenitores para el hijo del deseo.

\section{CONCLUSIONES}

Aunque en el marco de la Biolegislación colombiana la comunidad LGBTI reclama que el matrimonio, la adopción homoparental y las técnicas de reproducción asistida constituyen derechos que no les deben ser negados, este no constituye el deseo de la

3. Magistrado ponente: Jorge Iván Palacio Palacio. La corte declaro exequibles apartes de los artículos 64,66 y 68 de la Ley 1098 de 2006 y 1 ㅇ de la Ley 54 de 1990 y precisó que las parejas del mismo sexo únicamente pueden adoptar cuando la solicitud recaiga en el hijo biológico del compañero o compañera permanente. 
totalidad de dicha población pues existe una contraparte que reconoce el derecho de los menores a nacer dentro de un hogar constituido por ambas figuras paternas, como así lo dicta la ley natural. En este sentido, si bien el debate sobre el matrimonio gay y la procreación en el marco de este tipo de uniones puede en ocasiones dar la impresión de que se trata de una reivindicación de todos los homosexuales 0 de todas las parejas constituidas por diferentes diversidades sexuales, género, orientaciones e identidades, la realidad es que no existe tal unanimidad en un sector que justamente hace gala a la diversidad.

Por otra parte, sin importar cuán buenas sean las intenciones o motivaciones que lleven a una pareja homosexual, tríos, o grupos poliamorosos, de conformidad a las orientaciones, identidades y diversidades sexuales, a querer adoptar o procrear hijos, es evidente dentro de la historia de la humanidad, que sólo las parejas heterosexuales se encuentran en condiciones de cubrir las necesidades específicas de un niño, siendo innecesario someterlos como conejillos de indias a experimentos sociales que sirven a los intereses de una agenda política o un determinado grupo de presión; partiendo además del hecho de que son seres humanos cuyos derechos son inalienables y a quienes por encima de todo se les debe garantizar una vida digna donde prime un respecto absoluto por su persona humana, su derecho al libre desarrollo de la personalidad, orientación e identidad sexual.

Una vez dicho esto, es menester, en el caso colombiano, empoderar al constituyente primario a través de un mecanismo de participación ciudadana como "el referendo", para que sea este quien tenga la potestad de aprobar o no la constitución de familias homoparentales capaces de adoptar o procrear hijos, bajo el entendido de que la familia conformada por padre y madre ha sido, es y seguirá siendo, la célula fundamental de la sociedad bajo la cual se funda el Estado, y la responsable de proteger y promover desde su seno el interés ulterior de los niños.

\section{REFERENCIASBIBLIOGRÁFICAS}

·Bao, A-M, Swaab, DF. (2011). Sexual differentiation of the human brain: Relation to gender identity, sexual orientation and neuropsychiatric disorders. Frontiers in Neuroendocrinology; pp. 32:214-226.

-Celis, LG. (2011). Las Ciencias Biomédicas del Siglo XXI. Crítica al determinismo genético. Nova; pp. 9(16):122-123.

-Decreto 149 de 2012 del 4 de Abril, Por medio del cual se modifica la estructura organizacional de la Secretaría Distrital de Integración Social. Disponible en http://www.alcaldiabogota.gov.co/sisjur/normas/ Norma1.jsp?i=46794.

-De Vries, GJ y Södersten, P. (2009). Sex differences in the brain: The relation between structure and function. Hormones and Behavior; pp. 55:589-596.

-Del Barco, JL. (1998). Bioética de la Persona Humana. Universidad de La Sabana: Chía.

-Delgado Castro, Á. (2004). La adopción por Homosexuales: Universidad de Navarra. Disponible en www.unav.edu/departamento/civil/files/file/civil/ castro_adopcion.pdf

-El Tiempo. (2015). Corte limita adopción gay a que uno de la pareja sea padre biológico. Disponible en http://www.eltiempo.com/politica/justicia/corte-diceno-a-adopcion-de-ninos-por-parejas-gay-/15268396 -Finkielstain, GP, Kim, MS, Sinali N, Nishitani M, Van Ryzin C, Hill SC, Reynolds JC, Hanna RM y Merke DP. (2012). Clinical characteristics of a cohort of 244 patientes with congenital adrenal hyperplasia. J Clin Endocrino Metb; 97(12):4429-4438.

Kac, E. (2005). Telepresence and Bio Art Networking Humans, Rabbits and Robots. Ann Arbor: University of Michigan Press.

-Kulshreshtha, B, Eunice, M, Ammini AC. (2012). Pubertal development among girls with classical congenital adrenal hyperplasia initiated on treatment at different ages. Indian $\mathrm{J}$ Endocrinal Metab. 16(4):599-603.

-LeVay, S.A (1991). Difference in hypothalamic structure between heterosexual and homosexual men. Science; 253: 1034-1037.

-Hamer, DH, Hu, S, Magnuson VL, Hu N, Pattatucci AML. (1993). A Linkage between DNA. Markers on the $X$ chromosome and Male Sexual Orientation. 
Science; 261:321-327.

-Hines, M. (2010). Sex-related variation in human behavior and the brain. Trends in Cognitive Sciences: 14(10): 448-456.

-Monroy, J. (2013). Técnicas de reproducción asistida y su incidencia en Colombia. Verba luris, 30, 135150.

-Online Mendelina Inheritance in Man (OMIM). An Online Catalog of Human Genes and Genetic Disorders Updated 5 June 2014. Disponible en http://www.omim.org/search?index=entry\&sort=sco re+desc\%2C+prefix_sort+desc\&start=1\&limit=10\&s earch=OMIM+306995+.

-Rahman, Q. (2005). The neurodevelopment of human sexual differentiation. Neuroscience and Biobehavioral Review; 29:1057-1066.

-Ric, G, Anderson, C, Risch, N, Ebers G. (1999). Male Homosexuality: Absence of Linkage to Microsatellite Markers at Xq28. Science; 284 (5414) : 665-667.

-Roselli, ChE, Larkynn, K, Schurunk, JM. (2004). Sexual partner preference, hypothalamic morphology and aromatase in rams. Physiology \& Behavior; 83:233-245.

-Samper, P. (1991). La fecundación asistida en Colombia: realidad y norma. Disponible en :

https://derechoprivado.uniandes.edu.co/component s/com_revista/archivos/derechoprivado/pri378.pdf -Sanz, J. (2014). La adopción homosexual y la fecundación asistida. Disponible en http://www. la patria.com/columnas/110601/la-adopcion-homo sexual-y-la-fecundacion-asistida

-Semana. (2014). La pareja que logró un histórico fallo para adoptar. Disponible en http://www.semana. $\mathrm{com} /$ nacion/articulo/la-pareja-de-lesbianas-quegano-tutela-para-adoptar/400753-3

-Viedma, I. (2002). Proyecto Genoma Humano. Implicaciones Éticas. Persona y Bioética; 6 (7):7384.

-Watson, JD y Crick, FHC. (1953). Molecular Structure of Nucleic Acids. A Structure for Deoxyribose Nuclei Acid. Nature; 171(4356):737738.

-Zárate, A. (2014). Biomedicina y biotecnología ante la violencia prenatal. Legislación comparada con el derecho español. Bogotá, Colombia: Ediciones de la
U-Lid Editorial.

-Zárate, A (2015) Programa Veredicto. T. V. "Decisión de la Corte Constitucional sobre adopción igualitaria". 23 de noviembre de 2015.

-Zaraté, A. Celis, LG. (2015). Implicaciones Bioéticas derivadas de las parejas del mismo sexo a las tecnologías provenientes de la Biomedicina y la Biotecnología, para la conformación de las familias Homoparentales. Persona y Bioética; 19(1):48-63. 